\title{
PENGARUH LINGKUNGAN KERJA DAN KELELAHAN KERJA TERHADAP PRODUKTIVITAS KERJA KARYAWAN BAGIAN PRODUKSI (studi kasus PT. Sumber Graha Sejahtera (SGS))
}

\author{
Mega Dahlia \\ Email : megadelia62@gmail.com
}

Prodi Manajemen, Sekolah Tinggi Ilmu Ekonomi Muhammadiyah Palopo

\begin{abstract}
Abstrak
Tujuan penelitian ini adalah untuk menganalisis pengaruh lingkungan kerja dan kelelahan kerja terhadap produktivitas kerja karyawan bagian produksi pada PT. Sumber Graha Sejahtera Kabupaten Luwu. Data dalam penelitian ini adalah data primer yang diperoleh melalui penyebaran kuisioner dan data sekunder PT. Sumber Graha Sejahtera. Penelitian ini menggunakan analisis regresi linear berganda dan pengujian hipotesisnya dilakukan dengan uji t dan uji $\mathrm{F}$. sebelum dilakukan analisis regresi linear berganda dan diuji hipotesisnya, terlebih dahulu dilakukan uji validitas dan uji reliabilitas. Hasil penelitian menunjukkan bahwa variabel lingkungan kerja berpengaruh positif tetapi tidak signifikan terhadap produktivitas kerja karyawan, sedangkan variabel kelelahan kerja berpengaruh positif signifikan terhadap produktivitas kerja karyawan. Variabel lingkungan kerja dan kelelahan kerja juga secara bersama-sama berpengaruh terhadap produktivitas kerja karyawan.
\end{abstract}

Kata kunci: Lingkungan Kerja, Kelelahan Kerja dan Produktivitas Kerja Karyawan

\section{PENDAHULUAN}

Suatu bentuk usaha tanpa manusia, tidak mungkin ada dan tidak dapat dibayangkan. Bagaimanapun sederhana ataupun kompleksnya suatu bentuk usaha, manusialah yang menjadi intinya. Segala bentuk usaha, akhirnya dapat disimpulkan sebagai suatu gerak dari manusia, oleh manusia dan untuk manusia. Dalam tatatata perusahaan, kita kenal faktor-faktor perusahaan yang terdiri dari modal, alat-alat kerja dan organisasi. Kedua faktor terakhir merupakan materi hidup, yaitu kerja, karena faktor kerja adalah hasil dari manusia. Manusia merupakan sumber daya yang paling utama dari pada aspek ekonomi dan teknologi. Manusia merupakan sumber daya yang paling penting dalam menjalankan roda perusahaan baik yang bersekala kecil, sedang maupun besar dan merupakan asset yang mempunyai fisik dan daya faktor dalam menggerakkan, mengatur dan memutuskan. Sehingga manusia adalah satu-satunya yang mampu melaksanakan fungsi manajemen berupa perencanaan, pengorganisasian, menggerakkan dan mengontrol agar perusahaan berjalan baik.
Manusia sebagai penggerak utama perusahaan dalam mencapai tujuan perusahaan merupakan sumber daya yang tidak dapat diganti fungsinya dengan peralatan lain, betapapun pesatnya perkembangan teknologi namun bila tidak ditunjang oleh sumber daya manusia yang berkualitas maka hasilnya tidak akan mungkin menjadi seperti yang diharapkan.

Melihat pentingnya manusia dalam pencapaian tujuan perusahaan maka diperlukan adanya penanganan sendiri terhadap sumber daya ini agar mereka dapat bekerja sesuai dengan apa yang diinginkan oleh pimpinan perusahaan. Dengan demikian pemeliharaan tenaga kerja mutlak diperlukan baik moral maupun fisik, dengan adanya lingkungan kerja yang baik, yang dapat memenuhi kebutuhan karyawan dengan sendirinya karyawan akan menyadari tanggung jawabnya terhadap perusahaan. Hal ini dapat digunakan sebagai faktor untuk meningkatkan semangat kerja karyawan. Dan dapat berguna untuk mencegah terjadinya kelelahan kerja dan kerugian pada perusahaan, sehingga dengan lingkungan kerja yang mendukung dan memenuhi kebutuhan karyawan dapat meningkat kegairahan kerja karyawan. 
Kelelahan adalah suatu mekanisme perlindungan tubuh agar tubuh terhindar dari kerusakan lebih lanjut sehingga terjadi pemulihan setelah istirahat. Istilah kelelahan biasanya menunjukkan kondisi yang berbedabeda dari setiap individu, tetapi semuanya bermuara kepada kehilangan efisiensi dan penurunan kapasitas kerja serta ketahanan tubuh.Tujuan utama suatu perusahaan adalah mencapai keuntungan yang maksimum, keuntungan ini akan tercapai bila adanya produktifitas kerja yang tinggi. Sedangkan hal tersebut akan tercapai apabila adanya kegairahan kerja dari karyawan dalam bekerja. Untuk itu diperlukan adanya lingkungan kerja yang baik. Lingkungan kerja bagi karyawan akan mempunyai dampak yang tidak kecil bagi jalannya operasi perusahan karena secara langsung dapat mempengaruhi kegairahan kerja karyawan. Dengan memperhatikan permasalahan diatas dan mengingat betapa pentingnya masalah lingkungan kerja bagi perusahaan, maka penulis tertarik untuk meneliti masalah yang ada hubungannya dengan lingkungan kerja pada PT. Sumber Graha Sejahtera (SGS) Kabupaten Luwu.

Menurut Herjanto (2007), produktivitas dapat digunakan sebagai tolak ukur keberhasilan suatu industri atau usaha kecil dan menengah (UKM) dalam menghasilkan barang atau jasa, jika semakin tinggi perbandingannya, maka semakin tinggi produk yang dihasilkan. Hasibuan (2010) menjelaskan bahwa yang dimaksud dengan produktivitas adalah perbandingan antara output dan input, di mana output harus mempunyai nilai tambah dan teknik pengerjaannya yang lebih baik. Peningkatan produktivitas juga menghasilkan peningkatan langsung pada standar hidup yang berada di bawah kondisi distribusi yang sama dan perolehan produktivitas yang sesuai dengan masukan tenaga kerja (Sedarmayanti, 2011).

Namun banyak perusahaan cenderung beranggapan keliru bahwa tingkat kinerja kerja karyawan hanya diukur proporsional berdasarkan ukuran paket kompensasi yang diberikan sehingga perusahaan mengabaikan faktor lingkungan kerja sebagai poin penting yang dapat memotivasi dan mendorong semangat kerja karyawan. Pendapat lain dari
Lestari, 2013 menjelaskan bahwa lingkungan kerja merupakan salah satu faktor yang dapat mempengaruhi baik buruknya kinerja karyawan. Lingkungan kerja merupakan situasi maupun kondisi yang ada dalam lingkungan pekerjaan itu sendiri seperti bagaimana perlakuan dari atasan, rekan kerja, bagaimana beban kerja yang diberikan, serta penghargaan bagi karyawan yang berprestasi dan lain sebagainya.

Karena dengan lingkungan kerja yang memenuhi syarat dan memenuhi kebutuhan karyawan dapat meningkatkan kegairahan kerja karyawan agar dapat bekerja dengan baik dan sesuai dengan yang diharapkan pimpinan perusahaan.Untuk itulah dari uraian di atas maka penulis tertarik untuk mengadakan penelitian dengan judul "pengaruh lingkungan dan kelelahan kerja terhadap produktivitas karyawan bagian produksi pada PT. Sumber Graha Sejahtera (SGS)".

\section{METODE PENELITIAN}

Penelitian ini dilaksanakan di PT. Sumber Graha Sejahtera Kabupaten Luwu yang terletak di Jalan Andi Maradang, Provinsi Sulawesi Selatan. Waktu penelitian ini dilakukan selama 2 bulan dari bulan Februari sampai dengan April.

Populasi yang digunakan dalam penelitian ini adalah seluruh karyawan bagian produksi pada PT. Sumber Graha Sejahtera Kabupaten Luwu, sedangkan dalam penentuan jumlah sampel menggunakan Sampling jenuh adalah teknik pengumpulan sampel bila semua anggota populasi digunakan sebagai sampel. Pengambilan sampel dilakukan kepada seluruh populasi yang berjumlahkan 50 responden dengan cara membagikan kuisioner.

Untuk menghitung dan menganalisis Analisis data dalam penelitian dilakukan dengan menggunakan bantuan program SPSS. Adapun persamaan dari regresi sederhana adalah sebagai berikut Sugiyono dan Wibowo (2002:35):

$\mathrm{Y}=\mathrm{a}+\mathrm{b}_{1} \mathrm{X}_{1}+\mathrm{b}_{2} \mathrm{X}_{2}+\mathrm{e}$

Keterangan :

$\mathrm{Y}=$ Kinerja karyawan

$\mathrm{a}=$ Konstanta dari persamaan regresi 
$\mathrm{b}_{1}=$ Koefisien regresi dari variabel X1

$\mathrm{b}_{2}=$ Koefisien regresi dari variabel X2

$\mathrm{X}_{1}=$ Lingkungan Kerja

$\mathrm{X}_{2}=$ Kelelahan Kerja

$\mathrm{e}=$ error/varibel penganggu

\section{HASIL DAN PEMBAHASAN Uji Parsial (Uji t)}

Uji $t$ dilakukan untuk mengetahui ada tidaknya pengaruh secara parsial variabel independen terhadap variabel dependen. Adapun tingkat signifikansi yang digunakan sebesar 0,05. Jika probabilitas $<0,05$ maka variabel independen secara parsial mempunyai pengaruh signifikan terhadap variabel dependen.

\begin{tabular}{|c|c|c|c|c|c|}
\hline \multirow[b]{3}{*}{ Model } & \multicolumn{2}{|c|}{$\begin{array}{l}\text { Hasil Uji t } \\
\text { Coefficients }^{\text {a }}\end{array}$} & & \multirow[b]{3}{*}{$t$} & \multirow[b]{3}{*}{ Sig. } \\
\hline & \multicolumn{2}{|c|}{ Unstandardized Coefficients } & $\begin{array}{c}\text { Standardized } \\
\text { Coefficients }\end{array}$ & & \\
\hline & $\mathrm{B}$ & Std. Error & Beta & & \\
\hline 1 (Constant) & 12,457 & 2.489 & & 5.006 &, 000 \\
\hline Lingkungan Kerja X1 & ,209 &, 115 & ,246 & 1.812 & ,076 \\
\hline Kelelahan Kerja X2 & , 122 & ,059 & ,278 & 2.048 & ,046 \\
\hline
\end{tabular}

a. Dependent Variable: Produktivitas Kerja karyawan $Y$

Sumber: Output SPSS 21.0, 2017

Berdasarkan tabel di atas, dapat diketahui nilai $\mathrm{t}_{\text {hitung }}$ untuk Lingkungan Kerja sebesar 1.812. Nilai ini akan dibandingkan dengan nilai $\mathrm{t}_{\text {tabel }}$ pada tabel distribusi t. Dengan $\alpha=0.05, \mathrm{df}=$ $\mathrm{n}-\mathrm{k}=50-3=47$, untuk pengujian dua sisi diperoleh nilai $t_{\text {tabel }}$ sebesar \pm 1.984 . Diketahui bahwa $t_{\text {hitung }}$ untuk $\mathrm{X}_{1}$ sebesar 1.812 berada diluar kedua nilai $\mathrm{t}_{\text {tabel }}(-1.678$ dan 1.678), maka $\mathrm{H}_{0}$ ditolak artinya Lingkungan Kerja secara parsial berpengaruh tetapi tidak signifikan terhadap Produktivitas Kerja karyawan. Berdasarkan tabel di atas, dapat diketahui nilai $\mathrm{t}_{\text {hitung }}$ untuk Kelelahan Kerja sebesar 2.048. Nilai ini akan dibandingkan dengan nilai $t_{\text {tabel }}$ pada tabel distribusi t. Dengan $\alpha=0.05, \mathrm{df}=\mathrm{n}$ $\mathrm{k}=50-3=47$, untuk pengujian dua sisi diperoleh nilai $t_{\text {tabel }}$ sebesar \pm 1.678 . Diketahui bahwa thitung untuk $\mathrm{X}_{2}$ sebesar 1.339 berada didalam kedua nilai $t_{\text {tabel }}(-1.678$ dan 1.678), maka $\mathrm{H}_{0}$ ditolak artinya Kelelahan Kerja secara parsial berpengaruh signifikan terhadap Produktivitas Kerja karyawan

\section{KoefisienDeterminasi $\left(\mathbf{R}^{2}\right)$}

Dalam suatu penelitian mengenai hubungan antar variabel tidak bebas dan variabel bebas sering ingin diketahui beberapa kekuatan X secara bersama-sama menerangkan perubahan pada Y. koefisien korelasi berganda (R) dan koefisien determinasi $\left(\mathrm{R}^{2}\right)$ dapat dilihat pada hasil SPSS ver.21 dibawah ini

\section{Uji KoefisienDeterminasi $\left(\mathbf{R}^{2}\right)$}

\begin{tabular}{|l|r|r|r|r|}
\hline & & & \\
Model & $\mathrm{R}$ & R Square & \multicolumn{1}{c|}{ Adjusted R Square } & \multicolumn{1}{c|}{ Std. Error of the Estimate } \\
\hline 1 &, $366^{\mathrm{a}}$ &, 134 &, 097 & 1,457 \\
\hline
\end{tabular}

a. Predictors: (Constant), Lingkungan Kerja X1, Kelelahan Kerja X2

Sumber: Output SPSS 21.0, 2018 
Dari tabel 4.17 hasil output SPSS di atas, diketahui nilai koefisien determinasi atau $R$ square sebesar 0,134 atau $13.4 \%$. Hal ini menunjukkan bahwa Lingkungan Kerja dan Kelelahan Kerja secara simultan (bersamasama) memberikan pengaruh terhadap variabel Produktivitas Kerja karyawan sebesar $13.4 \%$ sedangkan sisanya $100 \%-13.4 \%=86.6 \%$ merupakan pengaruh dari variabel lain

\section{PEMBAHASAN HASIL PENELITIAN}

\section{Variabel Lingkungan Kerja $\left(X_{1}\right)$}

Berdasarkan hasil PT. Sumber Graha Sejahtera Kabupaten Luwu yang dianalisis dengan mengunakan analisis regresi linear berganda juga menunjukkan bahwa Lingkungan Kerja mempunyai pengaruh tapi tidak signifikan terhadap Produkivitas Kerja Karyawan (nilai $t_{\text {hitung }}<$ $\mathrm{t}_{\text {tabel }}$ yaitu $1.812<1.678$ dan signifikasi $\mathrm{t}=$ $0.076>0.05)$.

Lingkungan kerja memiliki pengaruh akan tetapi (tidak signifikan) terhadap Produktivitas Kerja Karyawan di PT. Sumber Graha Sejahtera Kabupaten Luwu. Hal ini dikarenakan pengaruh lingkungan kerja seperti keamanan ditempat kerja dan fasilitas yang diberikan perusahaan untuk para karyawan di PT. Sumber Graha Sejahtera Kabupaten Luwu kurang mendukung karyawan untuk bekerja lebih optimal yang diambil dari hasil tanggapan responden.

\section{Variabel Kelelahan Kerja $\left(\mathbf{X}_{2}\right)$}

Berdasarkan hasil PT. Sumber Graha Sejahtera Kabupaten Luwu yang dianalisis dengan mengunakan analisis regresi linear berganda juga menunjukkan bahwa Kelelahan Kerja mempunyai pengaruh signifikan terhadap Produkivitas Kerja Karyawan (nilai $t_{\text {hitung }}<\mathrm{t}_{\text {tabel }}$ yaitu $2.048<1.678$ dan signifikasi $\mathrm{t}=0.046>$ $0.05)$.

Kelelahan kerja memiliki pengaruh dan signifikan terhadap produktivitas kerja karyawan pada PT. Sumber Graha Sejahtera Kabupaten Luwu. Hal ini berdasarkan hasil dari tanggapan responden seperti saat sedang bekerja sering merasa berat dibagian kepala dan merasa kaku dibagian bahu. Tentuya hal ini perlu diperhatikan oleh PT.Sumber Graha

\section{SIMPULAN DAN SARAN SIMPULAN}

Berdasarkan hasil analisis yang dilakukan pada penelitian ini, maka dapat diperoleh hasil kesimpulan sebagai berikut :

1. Lingkungan kerja memiliki pengaruh akan tetapi (tidak signifikan) terhadap Produktivitas Kerja Karyawan di PT. Sumber Graha Sejahtera Kabupaten Luwu. Hal ini dikarenakan pengaruh lingkungan kerja seperti keamanan ditempat kerja dan fasilitas yang diberikan perusahaan untuk para karyawan di PT. Sumber Graha Sejahtera Kabupaten Luwu kurang mendukung karyawan untuk bekerja lebih optimal yang diambil dari hasil tanggapan responden. Penelitian ini didukung oleh hasil penelitian Prasetyo Harvy Budihardjo,Victor P.K Lengkong dan Lucky O.H. Dotulong (2017.

2. Kelelahan kerja memiliki pengaruh dan signifikan terhadap produktivitas kerja karyawan pada PT. Sumber Graha Sejahtera Kabupaten Luwu. Hal ini berdasarkan hasil dari tanggapan responden seperti saat sedang bekerja sering merasa berat dibagian kepala dan merasa kaku dibagian bahu. Tentuya hal ini perlu diperhatikan oleh PT.Sumber Graha Sejahtera Kabupaten Luwu agar menjadi pertimbangan bagaimana seharusnya beban yang diberikan kepada karyawan tidak melampaui batas kemampuan agar tidak terjadi hal-hal yang tidak diinginkan. Penelitian ini didukung leh hasil penelitian Kindangan P.Elia, Johan Josephus dan Ardiansa.T. Tucunan (2014).

\section{SARAN}


Memperhatikan adanya beberapa kesimpulan yang telah disampaikan maka bagi penelitian selanjutnya perlu memperhatikan beberapa saran berikut ini :

1. Dari hasil penelitian ini, dapat diketahui bahwa variabel lingkungan kerja dan kelelahan kerja mempengaruhi peningkatan produktivitas kerja karyawan. Namun hal ini masih kurang dimaksimalkan oleh PT. Sumber Graha Sejahtera Kabupaten Luwu. Oleh karena itu diharapkan untuk terus meningkatkan produktivitas kerja karyawan. Hal ini dapat dilakukan terus menerus dengan memberikan semangat dan motivasi bagi karyawan sehingga dapat meningkatkan produktivitas kerja karyawan.

Dari hasil penelitian ini, dapat diketahui bahwa variabel lingkungan kerja memberikan pengaruh positif tetapi tidak signifikan. Oleh karena itu PT. Sumber Graha Sejahtera Kabupaten Luwu diharapkan untuk mengatasi lingkungan kerja terutama untuk pembagian kerja secara adil sesuai dengan kemampuan karyawan agar dapat meningkatkan produktivitas kerja karyawan.

\section{DAFTAR PUSTAKA}

A.A Anwar Prabu Mangkunegara, Tahun 2006. Perencanaan dan Pengembangan Sumber Daya Manusia, Pen. PT Refika Aditama.

Akinyele, dan Taiwo, Samuel., 2010. "Startegic Marketing Management of Oil and Gas Industry: A Review of Literature", Journal of Business Management and Economics, Vol. 1, no. 1, pp. 001-009.

Anoraga, P. 2009. Psikologi Kerja. Jakarta: Rineka Cipta.

Atmosoeprapto,K. 2001. Produktivitas Aktualisasi Budaya Perusahaan, Penerbit Gramedia, Jakarta.
AzaraShaheen, S. M. H. Naqvi, et al. 2013. "Employess Training and Organizational Performance: Medition By Employess Performance." Interdisciplinary Journal Of Contemporary Research In Business(4); 490-503.

Deci. E. L \& Ryan R.M. 2000. The What and Why Of Goal Persuit: Human Nedds the sel-Determination of Behavior. U.S. Lawrence Erlbaum Associaties, Inc.

Edy Sutrisno, 2014. Manajemen Sumber Daya Manusia. Cetak Ke Enam. Pranada Media Group, Jakarta.

Eka Idham Lip K Lewa dan Subowo. 2005. Pengaruh Kepemimpinan, Lingkungan Kerja Fisik, dan Kompensasi Terhadap Kinerja Karyawan Di PT. Pertamina (PERSERO) Daerah Operasi Hulu Jawa Bagian Barat. Cirebon: Sinergi Edisi Khusu on Human Resources, 2005.

Hasibuan. 2010. Manajemen Sumber Daya Manusia. Jakarta: Bumi Aksara

Herjanto, Eddy. 2007. Manajemen Operasi. Jakarta Grasindo.

Hotmatua R. 2006. "Hubungan Faktor Individu dan Postur Tubuh dengan Kelelahan Kerja pada Pekerja Bongkar Muat PT Kirana Sapta Angkola Timur Kabupaten Tapanuli Selatan Tahun 2009."Skripsi, Fakultas Kesehatan USU.

Iftikar Z, Sutalaksana. 2005. Teknik Perancangan Sistem Kerja. Bandung. ITB

Lestari, Ika. 2013. Pengembangan Bahan Ajar Berbasis Kompetensi. Padang: Akademia 
Mahmudi, 2005. Manajemen Kinerja Sektor Publik. Yogyakarta: UPP AMP YKPN.

Moeleong, Lexy. 2002. Metodologi Penelitian Kualitatif. Bandung: PT. Remaja Rosdakarya

Newstrom, John W., Davis, Keith. 2007. Perilaku Dalam Organisasi. Edisi Ke Tujuh. Jakarta: Erlangga.

Nitisemito. Alex S. 2000. Manajemen Personalia: Manajemen Sumber Daya Manusia, Ed 3. Ghalila Indonesia, Jakarta.

Oei, Istijanto. 2010. Riset Sumber Daya Manusia. Gramedia Pustaka Utama. Edisi Revisi.

Robbins SP, dan Judge. 2007. Perilaku Organisasi. Jakarta: Salemba Empat Hal 22.

Schultz, D., Schultz, S E. 2006. Psychology \& Work Today Ninth Edition. New Jersey: Pearson Education. Inc.

Sedarmayanti. 2009. Sumber Daya Manusia dan Produktivitas Kerja. Bandung: CV Maju Mundur.

Sedarmayanti. 2011. Manajemen Sumber Daya Manusia, Reformasi Birokrasi dan Manajemen Pegawai Negeri Sipil (cetakan kelima). Bandung: PT Refika Aditama

Simanjuntak, P. J. 1985. Pengantar Ekonomi Sumber Daya Manusia. Lembaga Penerbit Fakultas Ekonomi UI.

Sinungan, Muchdarsyah. 2003. Produktivitas Apa dan Bagaimana. Bandung: Bumi Aksara.

Siswanto, H.B. 2006. Pengantar Manajemen. Jakarta: Bumi Aksara

Sritomo Wignjosoebroto, 2000. Teknik Analisis Untuk Peningkatan Produkttivitas
Kerja Dalam Ergonomi Studi Gerakan dan Waktu, Institute Teknologi Sepuluh November Surabaya.

Sugiyono. 2007. Metode Penelitian Bisnis. Bandung: Alfabeta , 2009. Metode Penelitian Kuantitatif, Kuantitatif dan R\&D, Bandung Alfabeta.

Suharto, Edi. 2008. Kebijakan Sosial Sebagai Kebijakan Publik. Bandung: Alfabeta.

Suharsimi, Arikunto. 2006. Prosedur Penelitian: Suatu Pendekatan Praktek. Jakarta: Rineka Cipta

Suma'mur. 2009. Hiegiene Perusahaan dan Keselamatan Kerja. Jakarta: CV Sagung Seto.

Tarwaka, Sholichul, Lilik Sudiajeng, 2004. Ergonomi Untuk Keselamatan. Kesehatan Kerja dan produktivitas. Surakarta: UNIBA PRESS 